\title{
A STUDY ON PROFILE OF ORALLY INGESTED POISONS IN SELF HARM (ATTEMPTED SUICIDE) AT TOXICOLOGY UNIT, GOVERNMENT STANLEY MEDICAL COLLEGE
}

\author{
Jayanthi Rangarajan', Gauthaman Chinnathambi Somanathan², Muralidharan Reddipalayam Srinivasan³, Raja Krishnaraj ${ }^{4}$, Sujatha \\ Srinivasan Mohanan', Arunkumar Porumbath Parambil Pankajakshan6, Sindhiya Jayachandran ${ }^{7}$
}

1 Professor and HOD, Department of Internal Medicine, Government Stanley Medical College, Chennai.

${ }^{2}$ Assistant Professor, Department of Medicine, Government Stanley Medical College, Chennai.

${ }^{3}$ Professor, Department of Medicine, Government Stanley Medical College, Chennai.

${ }^{4}$ Assistant Professor, Department of Medicine, Government Stanley Medical College, Chennai.

${ }_{5}^{5}$ Assistant Professor, Department of Medicine, Government Stanley Medical College, Chennai.

${ }^{6}$ Post Graduate, Department of Medicine, Government Stanley Medical College, Chennai.

${ }^{7}$ Post Graduate, Department of Medicine, Government Stanley Medical College, Chennai.

\begin{abstract}
BACKGROUND

This is an observational study to know the profile of orally ingested poisons in cases of self-harm (Attempted suicide).[1][2] METHODS

This was a prospective observational study done from February 2015 - August 2015 in Government Stanley Hospital, at toxicology unit. The study included 100 patients above 13 years of age, presented with alleged history of ingestion of oral poisons with intention of self-harm/committing suicide. We excluded tablet poisoning, accidental ingestion and suspected or proven homicide cases. A detailed study on profile of poisons, preference patterns, social and demographic profile such as each patient's age, gender, occupation, income and education, reason for self-harm.[1] History of underlying psychiatric disorder.[3] etc. were studied. Data recorded and analysed.
\end{abstract}

\section{RESULTS}

Among 100 patients we studied, 53 were males and 65 patients belonged to 20-39 age group, of these 47 consumed rodenticides and 61 belonged to low socioeconomic status; 8 out of 100 patients expired, in that 5 were males.

\section{CONCLUSIONS}

Our study concluded that males are predominant in patients presenting with alleged history of consumption of orally ingested poisons in an attempt at self-harm (Attempted suicide).[1][2] Most preferred poisons were rodenticides, pesticides and corrosives. Suicidal intention is stronger in males.

\section{KEYWORDS}

Self-Harm, Orally Ingested Poisons, Attempted Suicide.

HOW TO CITE THIS ARTICLE: Rangarajan J, Somanathan GC, Srinivasan MR, et al. A study on profile of orally ingested poisons in self harm (attempted suicide) at toxicology unit, Government Stanley Medical College. J. Evolution Med. Dent. Sci. 2016;5(36):

2087-2091, DOI: $10.14260 /$ jemds/2016/490

\section{INTRODUCTION}

Suicide is a tragic and potentially preventable public health problem. Attempted suicide.[2] is a common clinical problem seen in general hospital setting and most commonly preferred mode is oral ingestion of poisons. Suicide is the third leading cause of death among young adults worldwide. There is a growing recognition that prevention strategies need to be tailored to the region-specific demographics of a country and to be implemented in a culturally-sensitive manner. There has been an increase in the rates of suicide in India over the years, although trend of both increases and decline in suicide rates have been present. The motives and modes of suicide are also distinct from western countries. Preventive strategies implemented at a community level and identifying vulnerable individuals may be more effective than global strategies.

Financial or Other, Competing Interest: None.

Submission 19-03-2016, Peer Review 13-04-2016,

Acceptance 20-04-2016, Published 03-05-2016.

Corresponding Author:

Dr. Jayanthi Rangarajan,

No. 6A, Sagar Srinivas, $2^{\text {nd }}$ Street,

Srinivasapuram,

Thiruvanmiyur,

Chennai-600041.

E-mail: rjayanthi@doctor.com

DOI: $10.14260 /$ jemds/2016/490
Suicides among the top three causes of death among youth worldwide. According to the WHO, every year almost one million people die from suicide and 20 times more people attempt suicide; a global mortality rate of 16 per 100,000 or one death every 40 seconds and one attempt every 3 seconds on average. Suicide worldwide was estimated to represent $1.8 \%$ of the total global burden of disease in 1998; in 2020 this figure is projected to be $2.4 \%$ in countries with market and former socialist economies. ${ }^{[4]}$ According to the most recent World Health Organization (WHO) data that was available as of 2011, the rates of suicide range from $0.7 / 100,000$ in the Maldives to $63.3 / 100,000$ in Belarus.

India ranks $43^{\text {rd }}$ in descending order of rates of suicide with a rate of 10.6/100,000 reported in 2009 (WHO suicide rates). The rates of suicide have greatly increased among youth and youth are now the group at highest risk in onethird of the developed and developing countries. The emerging phenomenon of "cyber-suicide" in the internet era is a further cause for concern; also because the use of new methods of suicide are associated with epidemic increases in overall suicide rates.[4]

Suicides make a substantial contribution to the numbers of premature deaths and to inform policies that might prevent suicide there is a need for improved knowledge about risk factors. Previous studies have used data from death certificates to investigate the relation 
between registrar general's social class and suicide. Before the second world war, there was an inverse gradient of social class with higher rates in social classes I and II than IV and V. Subsequent findings have described a "U shaped" distribution with higher rates in both social classes I and V, though this may be a cohort effect apparent only in older age groups.

The most recent studies have found higher rates in lower social classes, though the relation does not look linear over the whole gradient of social class. There are also other variables that relate to socioeconomic status including educational attainment and standard of living, where housing tenure and access to a car can be used as indicators. These have been little studied in relation to suicide. There is evidence that the availability of methods for suicide can influence rate of suicide and poisoning with car exhaust fumes is becoming an increasingly common method. It is therefore possible that access to a car would increase the risk of suicide after adjustment for other socioeconomic differences between people.[5]

A strong association between unemployment and suicide has also been described in various studies that used different approaches. There is always the concern, however, that the relation could be confounded by psychiatric disorder, alcohol or substance misuse or unspecified personality characteristics. The strongest evidence so far comes from the office for National Statistics Longitudinal Study, in which this association persists in a longitudinal design with a rate ratio of 1.7 (95\% confidence interval 1.0 to 2.5 ). Unemployment tends to be more common in those with lower socioeconomic status and may explain some or all of the association between socioeconomic status and suicide.[5]

Suicide is nevertheless a private and personal act and a wide disparity exists in the rates of suicide across different countries. A greater understanding of region-specific factors related to suicide would enable prevention strategies to be more culturally sensitive. This focus is also highlighted in the September 10, 2012 World Suicide Prevention Day theme "Suicide Prevention across the Globe: Strengthening Protective Factors and Instilling Hope." This qualitative review explores the historical and epidemiological aspects of suicide in with a special focus on India. We hope that exposure of the problem will facilitate primary prevention planning strategies. Majority of people who experience suicidal ideation do not carry it through. Some may however, make attempt. Some suicidal ideations are deliberately planned to failed or to be discovered, while others might be carefully planned to succeed.[6] A nonfatal suicide attempt is the strongest known clinical predictor of eventual suicide.[7]

\section{OBJECTIVES}

To study the clinical and social demographic profile of orally ingested poisons in cases of self-harm/attempted suicide.

To identify possible factors behind the suicide attempt in patients presenting with alleged history of ingestion of oral poisons in cases of self-harm/attempted suicide.

\section{METHODOLOGY}

Institutional Ethical Committee approval and informed consent from study subjects were obtained. This was a prospective observational study done from February 2015August 2015 in Government Stanley Hospital at the toxicology unit of IMCU. Our study included 100 patients presented with alleged history of consumption of oral poisons for attempted suicide with intention of self-harm. We excluded tablet poisoning, accidental ingestion and suspected or proven homicide cases. A detailed study on each patient's age, sex, occupation, income, education, reason for attempting suicide, previous history of any psychiatric disorders, etc. are undertaken. Data recorded and analysed.

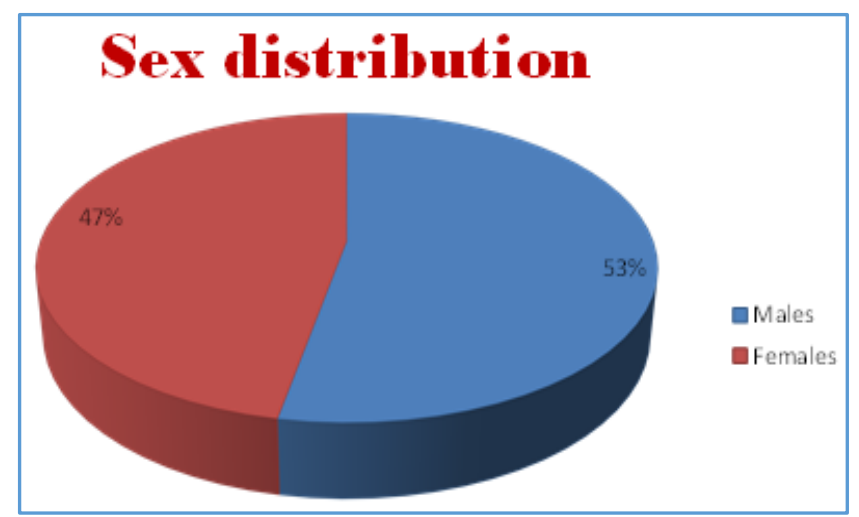

Fig. 1: PIE Chart Depicting Sex Distribution in Study Population

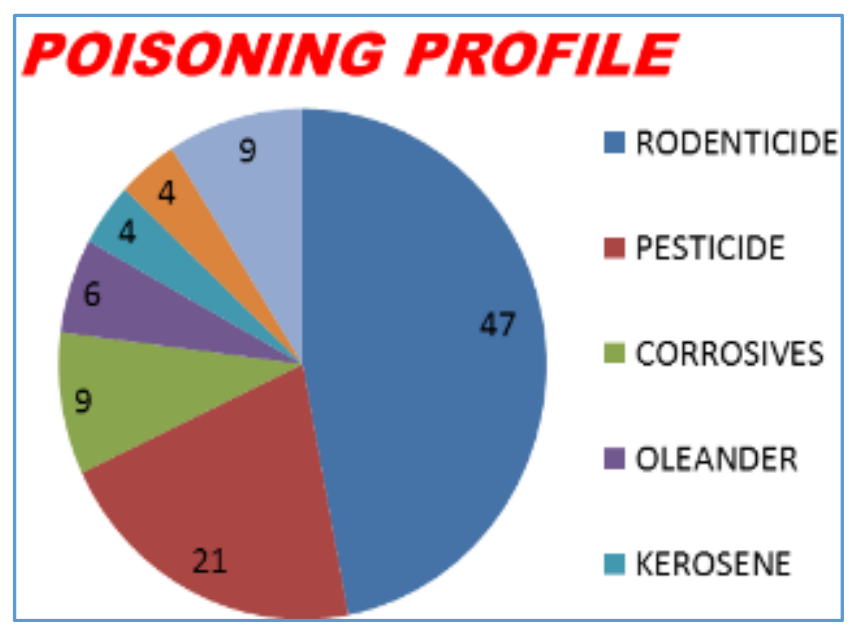

Fig. 2: PIE Chart Depicting the Poisoning Profile of the Study Population

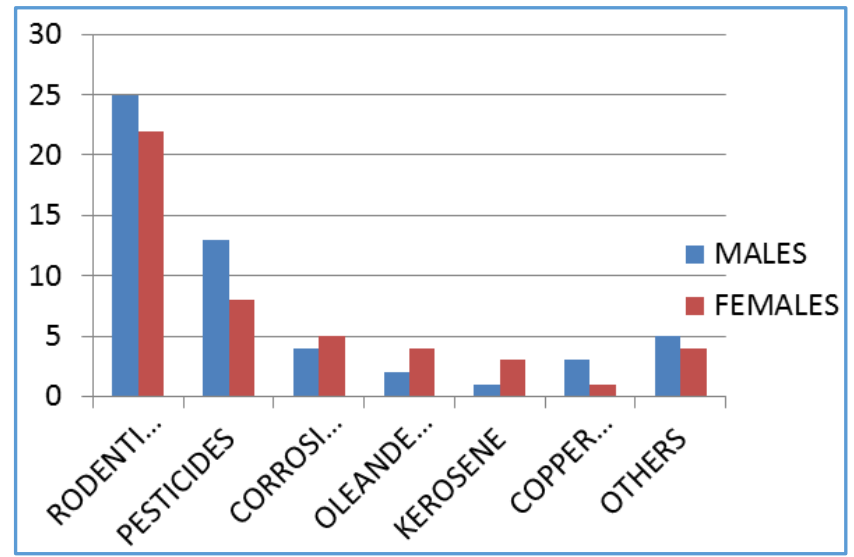

Fig. 3: Depicting Sex Distribution in Individual Poisoning

A gastrointestinal tract irritant causing mucosal damage, epigastric pain and discomfort. 


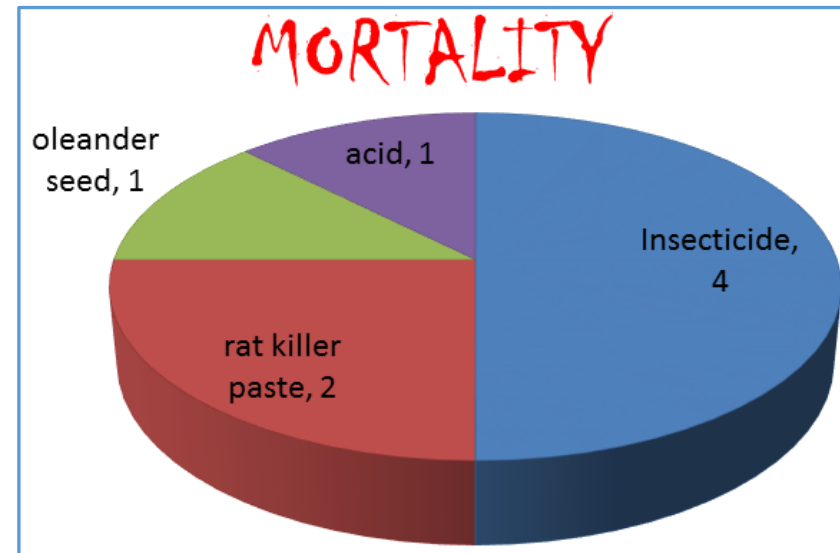

Fig. 4: PIE Chart Depicting Mortality Rates among Poisons

\section{Socioeconomic Status (Modified Kuppuswamy Classification) \\ - Lower-7.}

- $\quad$ Upper lower - 54 .

- $\quad$ Lower middle - 23.

- Upper middle - 14 .

- Upper - 2.

History of Previous Psychiatric Illness

- $\quad$ Out of 100 patients, 2 had psychiatric illness (Paranoid schizophrenia and bipolar disorder).[3][1][7]

\section{REASONS FOR ATTEMPTED SUICIDE}

\begin{tabular}{|c|c|c|}
\hline No. & Reason for Suicide Attempt & Number of Patients \\
\hline 1 & Family Disputes & 51 \\
\hline 2 & Debt & 16 \\
\hline 3 & Educational Problems & 7 \\
\hline 4 & Love Affairs & 8 \\
\hline 5 & Under Influence of Alcohol & 9 \\
\hline 6 & Unidentified & 9 \\
\hline \multicolumn{2}{|c|}{ Table 1: Table Depicting Reasons for Attempted Suicide } \\
\hline
\end{tabular}

\begin{tabular}{|c|c|c|c|c|}
\hline Journal & $\begin{array}{c}\text { Journal of Applied } \\
\text { Pharmaceutical Science Vol. } \\
3\end{array}$ & $\begin{array}{l}\text { Indian Journal of } \\
\text { Critical Care } \\
\text { Medicine }\end{array}$ & $\begin{array}{c}\text { Asia Pacific Journal } \\
\text { of Medical } \\
\text { Toxicology } \\
\end{array}$ & $\begin{array}{c}\text { Original Paper from } \\
\text { Thrissur Medical } \\
\text { College }\end{array}$ \\
\hline Place & Tamilnadu & Karnataka & Mumbai & Kerala \\
\hline Study & Retrospective & Retrospective & Cross Sectional & Retrospective \\
\hline Year & $2009-2012$ & 2002 & $2012-2013$ & 1995 \\
\hline Sex & Males & Males $(3 ; 1)$ & Males & Males \\
\hline Age & $21-30$ & $20-29$ & $20-29$ & $20-29$ \\
\hline $\begin{array}{c}\text { Commonest } \\
\text { Agent }\end{array}$ & OPC & OPC & Pesticides & $\begin{array}{l}\text { Carbamate } \\
\text { (Furadan) }\end{array}$ \\
\hline Occupation & Manual Labourers & Manual Labourers & & \\
\hline
\end{tabular}

\begin{tabular}{|c|c|c|c|}
\hline No. & $\begin{array}{l}\text { Medical } \\
\text { College }\end{array}$ & $\begin{array}{l}\text { Most Common } \\
\text { Poisons }\end{array}$ & Unique Poison \\
\hline 1 & Salem & $\mathrm{OPC}$ & $\begin{array}{l}\text { Cow Dung Powder, } \\
\text { Oduvanthalai }\end{array}$ \\
\hline 2 & Kilpauk & Rodenticide $>0$ PC & \\
\hline 3 & Chengalpattu & Organo Chlorines & Oduvanthalai \\
\hline 4 & Madurai & OPC > Rodenticide & \\
\hline 5 & Trichy & $\begin{array}{c}\text { OPC } \\
\text { (Monocrotophos) }\end{array}$ & \\
\hline 6 & Thirunelveli & $\mathrm{OPC}$ & \\
\hline 7 & Thanjavore & $\begin{array}{c}\text { OPC }>\text { Rodenticide } \\
\quad>\text { Oduvanthalai }\end{array}$ & Oduvanthalai \\
\hline 8 & Coimbatore & $\begin{array}{c}\text { Cowdung Powder> } \\
\text { OPC } \\
\end{array}$ & Cowdung Powder \\
\hline 9 & Kanyakumari & OPC >Al. Phosphide & $\begin{array}{l}\text { Aluminium } \\
\text { Phosphide }\end{array}$ \\
\hline \multicolumn{4}{|c|}{$\begin{array}{c}\text { Table 3: Table Depicting Trends of Poisoning } \\
\text { in Various States of India }\end{array}$} \\
\hline
\end{tabular}

\section{DISCUSSION}

\section{Commonly Ingested Poisons}

\section{Organophosphorus Poisoning}

Organophosphate (OP) compounds are a diverse group of chemicals used in both domestic and industrial settings. Examples of organophosphates include insecticides (Malathion, parathion, diazinon, fenthion, dichlorvos, chlorpyrifos, ethion), nerve gases (Soman, sarin, tabun, VX), ophthalmic agents (Echothiophate, isoflurophate), and anthelmintics (Trichlorfon). Herbicides (Tribufos [DEF], merphos) are tricresyl phosphate-containing industrial chemicals.

Worldwide mortality studies report mortality rates from 3$25 \%$. The compounds most frequently involved include malathion,

dichlorvos,

trichlorfon,

and fenitrothion/malathion. Mortality rates depend on the type of compound used, amount ingested, general health of the patient, delay in discovery and transport, insufficient respiratory management, delay in intubation and failure in weaning off ventilatory support.

\section{Rodenticide Poisoning}

Rodenticides are a heterogeneous group of compounds that exhibit markedly different toxicities to humans and rodents. They are among the most toxic substances regularly found in homes. Before the mid-20 th century, heavy metals (Arsenic, thallium) were the often-used agents. Since the mid-20th century, anticoagulant substances have been the mainstays of rodenticide products. In 2014, anticoagulant rodenticides constituted 8833 of the 11,309 case mentions of exposure to rodenticides recorded in the National Poison Data System (NPDS), administered by the American Association of Poison Control Centres (AAPCC). The predominant rodenticide exposure is anticoagulant rodenticides, generally the superwarfarin type.

Metal rodenticides produce serious toxicity and many produce long-term sequelae. Thallium and arsenic are responsible for severe peripheral neuropathies and fatalities have occurred; thus, the prognosis is guarded and depends on the speed of response. Fluoroacetate and zinc phosphide intoxications are potentially fatal. With no true antidote therapy, the mortality rate is considerable. Phosphorus intoxication produces serious corrosive injuries and may require extensive reconstructive surgery. 


\section{Copper Sulphate Poisoning}

Copper sulphate is one of the salts of copper. It is used in the making of various types of insecticides, herbicides, fungicides and algaecides. It is used as an analytical reagent, dye industry, leather, painting, gold industries. It is commonly used as a suicidal agent. Oral route is the main cause for local and systemic toxicity. Other modes of entry are through skin, eye and inhalation. The clinical profile can be asymptomatic on one end to life-threatening complications and death on the other end. Copper sulphate is an irritant. The usual routes by which humans can receive toxic exposure to copper sulphate are through eye or skin contact as well as by inhaling powders and dusts. Skin contact may result in itching or eczema. Eye contact with copper sulphate can cause conjunctivitis, inflammation of the eyelid lining, ulceration, and clouding of the cornea.

Upon oral exposure, copper sulphate is moderately toxic. According to studies, the lowest dose of copper sulphate that had a toxic impact on humans is $11 \mathrm{mg} / \mathrm{kg}$ of its irritating effect on the gastrointestinal tract. Vomiting is automatically triggered in case of the ingestion of copper sulphate. However, if copper sulphate is retained in the stomach, the symptoms can be severe. After 1-12 grams of copper sulphate are swallowed, such poisoning signs may occur as a metallic taste in the mouth, burning pain in the chest, nausea, diarrhoea, vomiting, headache, discontinued urination, which leads to yellowing of the skin. In cases of copper sulphate poisoning, injury to the brain, stomach, liver or kidneys may also occur.

\section{Hydrocarbons Poisoning}

Exposure to hydrocarbons is common in modern society. Hydrocarbons are easily accessible in products such as gasoline, turpentine, furniture polish, household cleansers, propellants, kerosene and other fuels. Although hydrocarbons include all compounds composed predominantly of carbon and hydrogen, the compounds of interest are derived from petroleum and wood. Most of the dangerous hydrocarbons are derived from petroleum distillates and include aliphatic (straight-chain) hydrocarbons and aromatic (benzene-containing) hydrocarbons. Other hydrocarbons such as pine oil and turpentine are derived from wood. Aspiration pneumonitis is the most common complication of hydrocarbon ingestion followed by Central Nervous System (CNS) and cardiovascular complications.

\section{Oleander Poisoning}

Cardiac glycosides are found in a diverse group of plants including Digitalis purpurea and Digitalis lanata (Foxgloves), Nerium oleander (Common oleander), Thevetia peruviana (yellow oleander), Convallaria majalis (Lily of the valley), Urginea maritime and Urginea indica (Squill), Strophanthus gratus (ouabain), Apocynum cannabinum (Dogbane), and Cheiranthus cheiri (Wallflower) has resulted in cardiac glycoside poisoning.

Toxicity may occur after consuming teas brewed from plant parts or after consuming leaves, flowers or seeds from plants containing cardiac glycosides. Significant toxicity usually is a result of suicide attempt or inappropriate selfadministration for the therapeutic purposes. Deliberate ingestion of yellow oleander seeds (Thevetia peruviana), known as "lucky nuts," is a popular method of self-harm in northern Sri Lanka. Thousands of cases are reported yearly with a case-fatality rate of untreated patients ranging between $5 \%$ and $10 \%$. Exposure rates may be higher in countries or communities that rely heavily on folk or herbal medicines including plants containing cardiac glycosides.

\section{Oduvanthalai Poisoning}

Self-poisoning through ingestion of Oduvanthalai is common in South India. Cleistanthus collinus (Karra) is a plant poison also called "oduvan" (Tamil), "Vadisaku" (Telugu) and Oduku (Malayalam). Ingestion of its leaves or a decoction of its leaves causes hypokalaemia (Kaliuresis and cardiac arrhythmias), metabolic acidosis, hypotension and hypoxia probably due to distal renal tubular acidosis, ARDS and toxin induced vasodilatation respectively. Hypokalaemia and acidosis probably also induces rhabdomyolysis resulting in myoglobinuric renal failure and neuromuscular weakness. Its effects are probably mediated by injury to the distal renal tubules, pulmonary epithelium and peripheral blood vessels due to glutathione depletion (Animal studies have shown benefit with $\mathrm{N}$-acetylcysteine).

Cleistanthin A and cleistanthin bare phytoconstituents of Cleistanthus collinus Roxb. Cleistanthin A and cleistanthin $B$ are arylnaphthalidelignans. They have been reported to be toxic substances responsible for poisoning. Cleistanthin A is also present in Phyllanthus toxodiifolius.

\section{Corrosive Poisoning}

Caustics and corrosives cause tissue injury by a chemical reaction. The vast majority of caustic chemicals are acidic or alkaline substances that damage tissue by accepting a proton (Alkaline substance) or donating a proton (Acidic substance) in an aqueous solution. Ingestions of caustic substances accounted for more toxic exposures than any other class of agents. The alkali drain cleaners and acidic toilet bowl cleaners are responsible for the most fatalities from corrosive agents. Approximately, $10 \%$ of caustic ingestions result in severe injury requiring treatment. Between $1 \%$ and $2 \%$ of caustic ingestions results in stricture formation.

\section{Cow Dung Powder Poisoning}

Cow dung, which has germicidal property, was used in ancient days to clean living premises in South India. Nowadays, people are using commercially available synthetic cow dung powder. It is locally known as "saani powder" in Tamil Nadu. It is freely available in homes and is sometimes accidentally consumed by children. It is available in two colours - yellow and green. Cow dung powder poisoning is common in districts of Tamil Nadu such as Coimbatore, Tirupur and Erode. Two types of cow dung powder are available - yellow powder (AURAMINE 0 - diarylmethane dye) and green powder (malachite green - triphenylmethane dye). Auramine causes centrilobular necrosis of liver. It is also a gastrointestinal tract irritant causing mucosal damage, epigastric pain and discomfort.

\section{CONCLUSION}

Our study concluded that males are dominating in number in patients presenting with alleged history of consumption of orally ingested poisons in self-harm (Attempted suicide) 
cases in Government Stanley Hospital and suicidal intention is more strong in males. Peak age group was 20-39 years. Rodenticides, Pesticides, Corrosives were the most preferred poisons. Among males, rodenticides and pesticides are most preferred, but among females corrosives, oleander seeds and kerosene dominating, probably explained by ease of accessibility and availability. Most of the patients belong to low socioeconomic status. In our study, majority of suicide attempts were attributed to family disputes. The mortality rate was $8 \%$ in the study population of two-thirds were males.

\section{REFERENCES}

1. Owens D, Horrocks J, House A. Fatal and non-fatal repetition of self-harm systematic review. $\mathrm{Br} \mathrm{J}$ Psychiatry 2002;181:193-9.

2. Hawton K, Catalan J. Attempted suicide ; a practical guide to its nature and management,Oxford university press 1987;2nd ed.
3. Harris EC,Barraclough B. Suicide as an outcome for mental disporders a meta-analysis.Br J Psychiatry 1997;170:205-28.

4. Rajiv Radhakrishnan,Chittarajan Andrade;Suicide An Indian Perspective,Indian J Psychiatry.2012;54(4):304319,doi:10.4103/0019-5545.104793.

5. Lewis G, Sloggett A.Suicide, deprivation, and unemployment: record linkage study. BMJ 1998;317(7168):1283-6.doi: http://dx.doi.org/10.1136/bmj.317.7168.1283.

6. McLaughlin, Columba. Suicide related behaviour understanding,caring and therapeutic responses chichester, England, John Wiley \& Sons.2007; $6^{\text {th }}$ ed.

7. Suominen K,Isometsä E, Suokas J, et al. Completed suicide after a suicide attempt: a 37 -year follow-up study. Am J Psychiatry 2004;161(3):562-3. 